\title{
Dissolution Model of Ball Milled Rice Straw Particles in 1-Ethyl-3-Methyl Imidazolium Acetate at Elevated Temperature
}

\author{
Hlaing Hlaing Myint ${ }^{1,2}$, Winarto Kurniawan ${ }^{1}$, Hirofumi Hinode ${ }^{1}$, Ni Ni Sein ${ }^{2}$, Chris Salim ${ }^{3}$ and Jeffrey S Cross ${ }^{1 *}$
}

${ }^{1}$ Department of International Development Engineering, Tokyo Institute of Technology, Meguro-Ku Tokyo, Japan

${ }^{2}$ Department of Chemistry, University of Yangon, 11041 Kamayut, Yangon, Myanmar

${ }^{3}$ Environmental Engineering, Surya University, Tangerang, Indonesia

\begin{abstract}
In Asia, rice straw residue left in fields after harvest is often burned which causes air pollution or anaerobically digested in the rice patty moist soil to yield methane a greenhouse gas. Effective and efficient process strategies are needed to convert straw into fuels and feedstock's which do not harm the environment. As a result, this study was undertaken to liquefy Japanese rice straw (RS) an abundant agricultural residue into a liquid after pre-treatment by ball-milling at various temperatures and develop a bioprocess model. Specifically, RS was ball milled into 75-100 $\mu \mathrm{m}$ size particles at temperatures of $60^{\circ} \mathrm{C}, 25^{\circ} \mathrm{C}$, and $-196^{\circ} \mathrm{C}$ (cryogenically) and dissolved by heating in 1-ethyl-3methylimidazolium acetate [Emim] [OAc] at different temperatures between $120^{\circ} 140^{\circ}$ and $160^{\circ} \mathrm{C}$ to understand the interactions between the process parameters. The milled RS powder particles were characterized by FTIR, XRD, BET analyzer and dissolution follow using optical microscopy. The particle dissolution was analyzed by measuring the particle light intensity ratio and particle cross-sectional area as a function of heating time. Higher milling temperature leads to amorphization of the RS cellulose accelerating dissolution. Measurement of the particle light intensity ratio was used to estimate the rice straw particles dissolution endpoint. A particle dissolution model indicated that ball milling temperature and [Emim][OAc] heating temperature strongly interacts influencing the dissolution time. To dissolve RS in [Emim][OAc] quickly, it important to reduce the crystallinity of the cellulose and increase the particle surface area by milling at higher temperature. It is believed this model would have applications to other biomass dissolution processes.
\end{abstract}

Keywords: Ionic liquid; Ball milling; Japanese rice straw; Dissolution; Particle; Model; Process; Microscopy

\section{Introduction}

Lignocellulosic agricultural crop residues i.e., rice straw, are an abundant underused raw material with potential for conversion to valuable chemical feedstock's and liquid fuels. However, lignocellulosic biomass is recalcitrant to biodegradation [1] and cannot be dissolved in water normally and in most organic solvents [2]. Developing effective and economical pretreatment processes for liquefaction and dissolution process models are extremely important for greater utilization of lignocellulosic biomass.

To date, biomass pretreatment research and development has focused on amorphization of the cellulose crystalline component and particle size reduction by milling to improve the dissolution rate. Ogura et al. revealed that ball milling converts rice straw containing cellulose from crystalline to amorphous material and results in physical changes [3]. Prolonged ball milling technique not only induces cellulose amphorization but also enhances the reactivity of cellulose during subsequent processing [4].

Previous work on ball milling of crystalline materials particularly on metallic alloy powders has shown that ball milling over a range of temperatures strongly influences alloy powder crystallinity and intermetallic mixing kinetics [5]. To our knowledge similar investigations on the physical and chemical changes in RS powder resulting from ball milling over a range of temperatures have not yet been reported. Pretreatment methods such as prolonged ball milling require high energy usage and it is unclear how ball milling conditions impact overall pretreatment energy consumption and subsequent dissolution.

Recently, many researchers have reported using dilute acid, [6] alkali [7] and chemical combinations for pretreatment and liquification of biomass including enzymatic hydrolysis [8]. Gírio et al. pointed out that the use of harsh chemical solvents such as acids and bases can cause problems with process equipment corrosion and generate environmental pollutants which have to be treated before disposal [9] Therefore, environmental friendly, novel green pretreatment processes using less energy that is also economical is needed.

Roger et al. reported that many ionic liquids are green solvents and can effectively dissolve biomass alone or by mixing without other chemicals [2]. For example, they confirmed 1-ethyl-3-methyl imidazolium acetate [Emim][OAc] was more effective than the other ionic liquids for lignocellulosic biomass dissolution [10]. Pretreatment using dilute acid and [Emim][OAc] of switchgrass has investigated and dissolved it when heated at $120^{\circ}-160^{\circ} \mathrm{C}$, which appears to be an effective temperature range. This result indicated [Emim] [OAc] was more effective for reducing cellulose crystallinity, increasing surface area and decreasing lignin content than dilute acid pretreatment [11]. In addition, a combined method of ammonia and [Emim] [OAc] pretreatment of rice straw exhibited higher cellulose dissolution rate and high sugar yields [12]. These publications outline the optimum

*Corresponding author: Jeffrey S Cross, Department of International Development Engineering, Tokyo Institute of Technology, 2-12-1 Ookayama, Meguro-Ku Tokyo, Japan, Tel: +81-3-5734-3723; E-mail: cross.j.aa@m.titech.ac.jp

Received November 09, 2015; Accepted November 23, 2015; Published November 27, 2015

Citation: Myint HH, Kurniawan W, Hinode H, Sein NN, Salim C, et al. (2015) Dissolution Model of Ball Milled Rice Straw Particles in 1-Ethyl-3-Methyl Imidazolium Acetate at Elevated Temperature. J Bioprocess Biotech 5: 260 doi:10.4172/21559821.1000260

Copyright: $\odot 2015$ Myint $\mathrm{HH}$, et al. This is an open-access article distributed under the terms of the Creative Commons Attribution License, which permits unrestricted use, distribution, and reproduction in any medium, provided the original author and source are credited. 
pretreatment process conditions for practicable dissolution of lignocellulosic biomass in [Emim] [OAc].

Other researchers have investigated dissolution rate of wood chips in [Emim] [OAc] by analyzing light changes of the material by using in-situ microscopy [13], however, this was not done quantitatively. Deguchi et al. confirmed complete cellulose dissolution in water at high temperatures and pressures by tracking the material relative brightness in micrographs without observing any swelling [14]. Subsequently, Olsson et al. investigated the swelling and dissolution rate of less crystalline portion of cellulose in [Emim][OAc] was very fast while some portions of cellulose showed slight swelling due to the inhomogeneity in the biomass [15]. The above published papers highlight the phase transformation of cellulose from crystalline to an amorphous material by ball milling. Secondly, usage of a green solvent such as [Emim] [OAc] on biomass generally proceeds by the treated material swelling then dissolution when heated. Finally, the endpoint of lignocellulosic biomass dissolution can be followed by microscopic observations of particle transparency (color contrast and intensity) as a function of heat treatment time. What is currently lacking in the literature is a systematic process model relating ball milling conditions and dissolution in an [Emim] [OAc] at various temperatures versus time.

As a result in this study, we propose a rice straw particle dissolution process time-based model investigating the relationship between ball milling temperature and by heat treatment in [Emim] [OAc] at various temperatures while following the dissolution using optical microscopy. The objective is to understand how the milling temperature speeds up the dissolution rate based upon the milled powder material properties.

\section{Materials and Methods}

\section{Sample preparation of RS powder with different grinding temperatures}

A stainless steel milling jar containing $3 \mathrm{~g}$ of $1 \mathrm{~cm}$ cut rice straw strips with a $25 \mathrm{~mm}$ stainless steel ball was kept in an oven for $2 \mathrm{hr}$ at either room temperature of $25^{\circ} \mathrm{C}$ or $60^{\circ} \mathrm{C}$, prior to grinding. Cryogenic $\left(-196^{\circ} \mathrm{C}\right)$ ball milling was also carried out by immersing the grinding jar containing the RS sample and a $25 \mathrm{~mm}$ sized stainless steel ball in liquid nitrogen for $10 \mathrm{~min}$ prior to milling. The RS sample was ground with a Mill Mixer (Retsch MM400, Germany) at a frequency of $28 \mathrm{~Hz}$ with a $25 \mathrm{~mm}$ stainless steel ball for $2 \mathrm{~min}$ followed by screening to achieve powder particles size ranges of 75-100 $\mu \mathrm{m}$ using a Vibratory Sieve-Shaker (ANALYSETTE 3, Germany). Ionic liquid 1-ethyl-3methylimidazolium acetate [Emim] [OAc] (97\% purity) was purchased from Sigma Aldrich and used without further purification. Dried rice straw stalks were obtained from a Machida City, Tokyo, Japan Tatami mat vendor in the Naruse district.

\section{Inorganic material analysis by ICP-AES}

The RS powder inorganic material was heated with an electric furnace at $500^{\circ} \mathrm{C}$ for $5 \mathrm{hr}$, dissolved with concentrated $\mathrm{HF}$ and analyzed by ICP-AES using standards (SPS 7800, Plasma Spectrometer, SII Seiko instruments Inc. Japan).

\section{FTIR analysis of milled rice straw powder}

Fourier transform infrared spectroscopy (FTIR) was performed using a FTIR spectro-photometer (JASCO 4100N FTIR, Japan). We mixed $1 \mathrm{mg}$ of rice straw powder with $100 \mathrm{mg}$ of potassium bromide $(\mathrm{KBr})$ in an agate mortar and compressed this mixture to form a pellet and measured it with 128 scans from 400 to $4000 \mathrm{~cm}^{-1}$ with a resolution of $4 \mathrm{~cm}^{-1}$.

\section{XRD analysis of milled rice straw powder}

Rice straw was characterized using an X-ray diffractometer (Rigaku Crop., Japan Multiflex XRD, Japan) with $\mathrm{Cu}$ Ka radiation $(\lambda=1.54 \AA$ ) set at $40 \mathrm{kV}$ and $20 \mathrm{~mA}$. The sample was scanned and intensity was recorded in a 2 theta range of $10-40^{\circ}$. The crystallinity index of the RS powder was calculated from the intensities of amorphous $\left(2 \theta=16^{\circ}\right)$ and crystalline regions $\left(2 \theta=22.5^{\circ}\right)$ of RS powder.

\section{Characterization of surface area}

A Brunauer, Emmett and Teller (BET) analyzer (AX1C-MP-LP, AUTOSORB-1, Japan) was used for measuring the sieved RS particle surface areas with nitrogen (LN2) adsorption/desorption isotherms at $-196^{\circ} \mathrm{C}$. The rice straw sample about $(\sim 0.5 \mathrm{~g})$ was degassed for 1.5 $\mathrm{hr}$ at $110^{\circ} \mathrm{C}$ under vacuum $(5 \mathrm{mmHg})$ to remove moisture and other contaminants. The analysis of surface areas was evaluated by using a three point adsorption method.

\section{Dissolution of rice straw in [Emim] [OAc]}

Prior to dissolution, sieved RS powder was put on a hot plate and dried at $140^{\circ} \mathrm{C}$ for $5 \mathrm{~min}$ on a glass slide to desorb moisture. For measurements of particle dimensions a Dino-Lite calibration grid was used and the magnification of approximately 60 times was calculated when using a 20X objective lens. In a typical dissolution trial, $0.01 \mathrm{mg}$ of rice straw was added to $10 \mu \mathrm{l}$ [Emim] [OAc] on a $1.0 \mathrm{~mm}$ thick glass slide and heated on a hot plate (HP-1S, As One, Japan) with set temperatures of $120^{\circ} \mathrm{C}, 140^{\circ} \mathrm{C}$ and $160^{\circ} \mathrm{C}$. The actual temperature of [Emim] [OAc] on the glass slide was measured with a thermocouple (NI USP TC01, Japan). We plotted the [Emim][OAc] temperature versus the setting hot plate temperature as shown in the supplementary data (Figure S1) and the set point temperature was $\left(5-10^{\circ} \mathrm{C}\right)$ higher than the [Emim] [OAc] glass slide temperature. To follow the dissolution process, the glass slide containing the RS particles in the IL drop was removed from the hot plate and observed periodically by an optical (Olympus BX41, Japan) microscope after fixed intervals of time. Micrographs of the RS particles were captured using a (Olympus E330 Hyper Crystal LCD digital camera, Japan). The particle area and color intensity were analyzed using ImageJ software. After observation, the slide was returned to the hot plate and heating continued for a fixed period of time. Observations were repeated until dissolution was achieved, that is, the particle became too transparent to view the particle dimension or circumference compared to the surrounding background.

\section{Results and Discussion}

\section{FTIR analysis}

The chemical and structural changes of milled RS powder at three different ball milling temperatures after sieving were analyzed by FTIR spectroscopy in the region of $400-4000 \mathrm{~cm}^{-1}$ Figure 1 (a). The spectra showed lignin bands at $1642 \mathrm{~cm}^{-1}$ and $\mathrm{C}-\mathrm{H}$ and O-H stretching band of cellulose at $3402 \mathrm{~cm}^{-1}$ was reduced after higher grinding temperature. This may be attributed hydrogen bond breakage of cellulose in the RS powder during milling [13]. For the sample ground at $60^{\circ} \mathrm{C}$, the spectrum of C-H stretching of cellulose at $3340 \mathrm{~cm}^{-1}$ became broader and the peak intensity was higher compared with the other grinding temperatures of $25^{\circ} \mathrm{C}$ and $-196^{\circ} \mathrm{C}$, which indicated higher amorphousity and lower moisture content based upon $\mathrm{O}-\mathrm{H}$ stretching band of water [16]. The methyl group $\left(\mathrm{CH}_{3}\right)$ between $2915 \mathrm{~cm}^{-1}$ and $2847 \mathrm{~cm}^{-1}$ indicates lignin [17]. The intensity of the peak attributed to $\mathrm{C}-\mathrm{O}-\mathrm{C}$ stretching at $1045 \mathrm{~cm}^{-1}$ slightly decreased due to the degradation of 
the cellulose during milling with bond shortening observed at 1309.6 $\mathrm{cm}^{-1}$ and $750.5 \mathrm{~cm}^{-1}$ [18]. The presence of silica was confirmed by the prominent $\mathrm{Si}-\mathrm{O}-\mathrm{Si}$ asymmetric and symmetric stretching peaks at 1090 and $460 \mathrm{~cm}^{-1}$, respectively, and the $\mathrm{Si}-\mathrm{O}$ deformation peak was also observed at $795 \mathrm{~cm}^{-1}$ [19]. Researchers reported that ball milling increased free hydroxyl groups by disrupting hydrogen bonding in the straw. These FTIR results confirm the chemical transformation such as hydrogen bonds breakage of cellulose, less water in RS powder resulting from processing at different ball milling temperatures.

\section{Effect of ball milling temperatures on rice straw crystallinity}

XRD measurements of RS powder milled at temperatures of $-196^{\circ}$, $25^{\circ}$ and $60^{\circ} \mathrm{C}$ showed crystalline cellulose peak intensity decreased with increasing milling temperature as shown in Figure 1(b). The peaks observed correspond to crystalline cellulose peaks of $(101),\left(101^{-}\right)$, and (002) planes which were confirmed independently by XRD analysis of rice straw powder. By calculating the peak height ratio between the intensity of the crystalline peak $\mathrm{I}(002)-\mathrm{I}$ (amor) and total intensity $\mathrm{I}(002)$ after subtraction of the background I(amor) by using the Segal method [20] which allows for quantitative comparison of the samples crystallinity,

$$
\text { Crystallinity Index, } \mathrm{Crl}=\frac{I(002)-I(\text { amor })}{I(002)}
$$

Where $\mathrm{I}(002)$ is the height of maximum peak at $22.5^{\circ}$ (in arbitrary units) and $\mathrm{I}$ (amor) is the height of the amorphous peak at $16^{\circ}$. The relative crystallinity indices of ball milled RS at $-196^{\circ} \mathrm{C}, 25^{\circ} \mathrm{C}$ and $60^{\circ} \mathrm{C}$ were $0.8,0.66$ and 0.58 respectively. The results indicated that the ball milling at higher temperature partially damages the crystalline cellulose

(a)
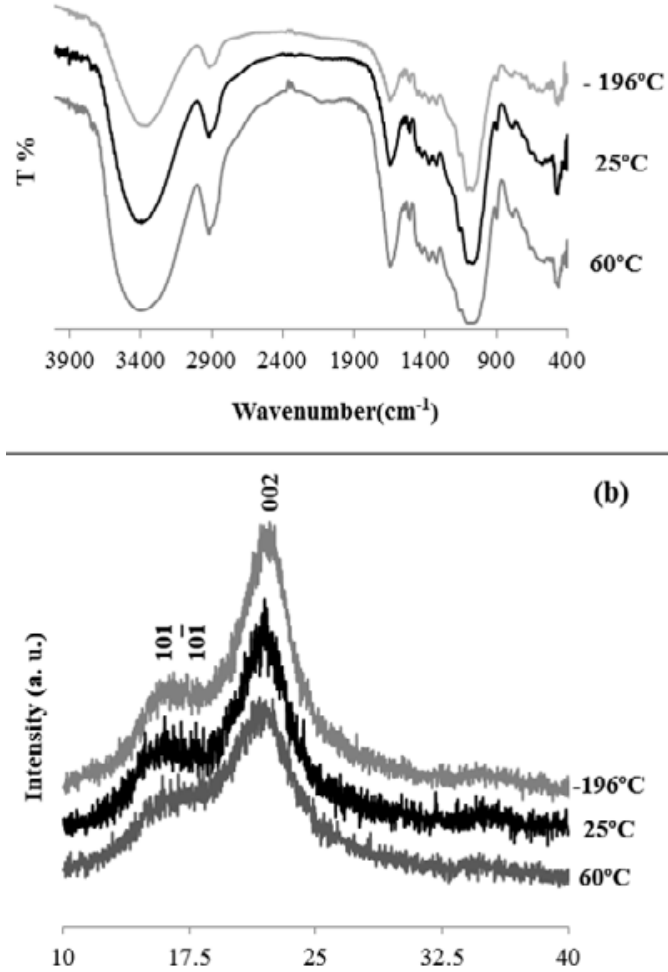

Figure 1: (a) FTIR spectra of ball milled rice straw powder and (b) X-ray diffraction patterns of ball milled rice straw powder under various ball milling temperatures at $-196^{\circ} \mathrm{C}, 25^{\circ} \mathrm{C}$ and $60^{\circ} \mathrm{C}$. converting it into a more amorphous material [13]. Therefore, particle cellulose crystallinity was reduced significantly when ball milled for just 2 min at higher milling temperatures.

\section{Characterization of surface area}

The impact of milling temperature on the RS surface areas was analyzed by BET. Surface area slightly increased from $2.0 \mathrm{~m}^{2} / \mathrm{g}$ at $-196^{\circ} \mathrm{C}$ to $2.6 \mathrm{~m}^{2} / \mathrm{g}$ at $25^{\circ} \mathrm{C}$ and then doubled to $5.2 \mathrm{~m}^{2} / \mathrm{g}$ when milled at $60^{\circ} \mathrm{C}$. Previously, published results report BET values of popped RS powder range between 1.5 and $3.0 \mathrm{~m}^{2} / \mathrm{g}$ due to the removal of hemicellulose [21]. It was observed higher milling temperature induces cracking on particle surface due to the stress arising on the fractured surfaces [22]. The impact on surface crystallinity and surface roughness has on dissolution will be presented in the next sections.

\section{SEM and optical microscopy analysis}

To better understand the milling temperature impact on the RS surface structure, the ball milled samples were observed with an optical microscope and SEM as shown in Figure 2(a-c) and 2(d-f). SEM image shown in Figure 2(a) indicated milled particles with cryogenic milling at $-196^{\circ} \mathrm{C}$ showed less surface roughness. A moderately rough surface was found at $25^{\circ} \mathrm{C}$ in Figure $2(\mathrm{~b}-\mathrm{e})$. The RS powder milled at $60^{\circ} \mathrm{C}$ had the most surface texture. Higher milling temperature increased surface area observed by optical microscope and SEM images in Figure 2(c-f).

We observed color differences in the milled rice straw powder related to the milling temperature, for example, when milled at $-196^{\circ} \mathrm{C}$ the RS powder exhibited a pale yellow color; both $60^{\circ}$ and $25^{\circ} \mathrm{C}$ milled powder were reddish yellow in color. The milled RS color changes showed a clear correlation with higher milling temperatures which is consistent with previous work [23].

\section{Swelling behavior of rice straw in ionic liquid}

Particle dissolution experiments were carried out in [Emim] [OAc] at $120^{\circ}, 140^{\circ}$ and $160^{\circ} \mathrm{C}$ (since dissolution experiments conducted at temperatures of $100^{\circ} \mathrm{C}$ or less did not proceed within one hour). Upon heating the RS particles in [Emim] [OAc], the particle's circumference gradually increased with an expanding cross-sectional area as the heating time increased. The results indicated the cellulose in RS plant wall was disrupted and dissolving. The particle cross-sectional area was monitored periodically from initial heating time $(0 \mathrm{~min})$ up to when

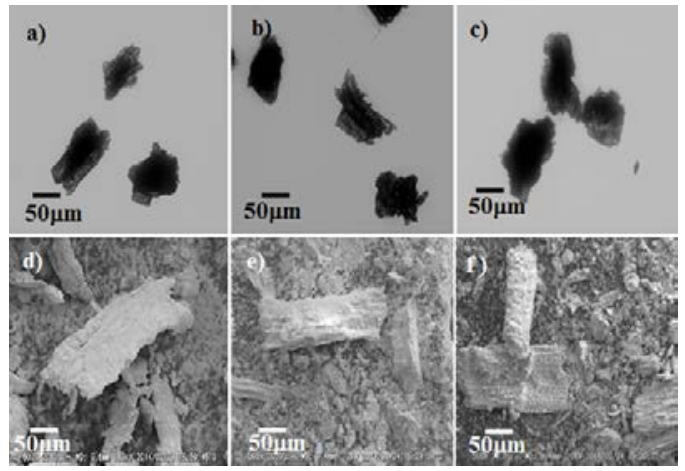

Figure 2: Optical microscope images of ball milled rice straw particles under different ball milling temperatures at (a) $-196^{\circ} \mathrm{C}$, (b) $25^{\circ} \mathrm{C}$, (c) $60^{\circ} \mathrm{C}$ and comparative study SEM morphology of structural breakage of ball milled RS particles at (d) $-196^{\circ} \mathrm{C}$, (e) $25^{\circ} \mathrm{C}$, (f) $60^{\circ} \mathrm{C}$. 
the particle became so transparent that it was considered to be literally dissolved i.e., when the particle area could no longer be measured. The particle area ratio was calculated by measuring the particle circumference and calculating the area as a function of heating time versus the initial area prior to heating by the following equation,

$$
\text { RS Particle Area ratio }=\frac{\text { RS Particle Area }(t)}{\text { RS Particle Area }(t=0)}
$$

The optical microscope images show (analysis by ImageJ software) the particle's perimeter/cross-sectional area increased due to swelling shown in Figure 3. The RS dissolution process for [Emim] [OAc] at $60^{\circ} \mathrm{C}$ and cryogenic milled particles is shown in Figures S2 and S3 (supplementary materials). In addition, equation 2 was used to calculate the RS particle swelling area ratio. The swelling area ratio of three different RS particles in [Emim] [OAc] as a function of baking times were plotted when heated at temperatures of $120^{\circ}$, $140^{\circ}$ and $160^{\circ} \mathrm{C}$ and fit using linear regression in (Figure 4 and Table 1a). Significant swelling as indicated by increasing the particle area resulted in the fastest dissolution time of 5 min when milled at $60^{\circ} \mathrm{C}$ and heated at $160^{\circ} \mathrm{C}$ in Figure S2 (supplementary material). In the Figure $4(\mathrm{a}-\mathrm{c})$, higher slopes indicate faster dissolution rate with greater particle swelling. These results clearly show particle swelling varies from 1.5 to 3 times as a function of IL heating and milling temperatures. In a previous study, heat treatment of biomass with [Emim][OAc] showed swelling precedes dissolution due to the IL molecules disrupt the hydrogen bond sheet cellulose inside of the cell wall [24]. Therefore, the higher ball milling temperature

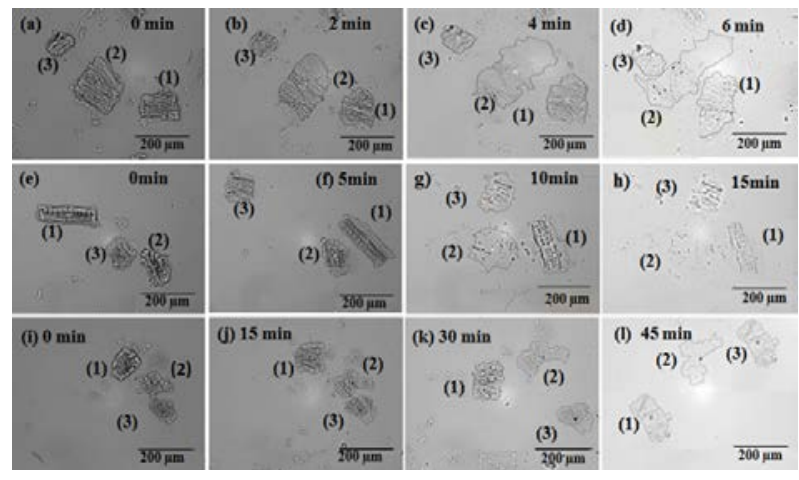

Figure 3: Dissolution of three RS particles ball milled at $25^{\circ} \mathrm{C}$ in [Emim] [OAc] heated at the $160^{\circ} \mathrm{C}$ vs time (a) $\mathrm{t}=0 \mathrm{~min}$ initial, (b) $2 \mathrm{~min}$, (c) $4 \mathrm{~min}$, (d) $6 \mathrm{~min}$; heated at $140^{\circ} \mathrm{C}$ vs. time (e) $\mathrm{t}=0 \mathrm{~min}$ initial, (f) $5 \mathrm{~min}$, (g) $10 \mathrm{~min}$ (h) $15 \mathrm{~min}$; heated at $120^{\circ} \mathrm{C}$ vs. time (i) $\mathrm{t}=0 \mathrm{~min}$ initial, (j) $15 \mathrm{~min}$, (k) 30 min, (l) 45 min. pretreatment appears to be effective in enhancing the dissolution rate and particle swelling.

\section{Changes of particle light intensity on dissolution}

Optical microscope images were used to characterize light intensity changes from the beginning of the RS particle dissolution time end point. The particle light intensity was calculated based upon integrating the average color contrast intensity between the particle and the [Emim][OAc] background intensity as shown by equation 3,

Particle Light intensity ratio $=\frac{\text { RS Particle Light intensity }(\mathrm{t})}{[\text { Emim] }][\mathrm{OAc}] \text { Light intensity }(\mathrm{t})}$

Particle light intensity ratio data was fit with linear regression in Figure 5 and summarized in Table $1 \mathrm{~b}$ when heated at temperatures of $120^{\circ} \mathrm{C}, 140^{\circ} \mathrm{C}$ and $160^{\circ} \mathrm{C}$. For each microphotograph, the background [Emim][OAc] light intensity was measured in three to five locations around the particle in order to calculate an average light intensity value since the background color changes slightly with time as the RS particle dissolved. The average particle light intensity ratio value ranged from 0.5 to 1.0 as the dissolution progressed during heating. When the light intensities of the particle and IL background are the same value, the light intensity ratio is 1.0 , which means that the particle dissolved in [Emim][OAc]. The light intensity ratio value linearly increases with the heating time in the [Emim] [OAc] and the slopes are strongly dependent upon the milling temperature. This evaluation method provides a method for estimating the particle dissolution end point time based upon quantitative analysis which has application for end point estimation in other types of biomass dissolution in agreement with ref. [14].

\section{Light intensity and end point determination}

Initially, the particles have a granular mosaic appearance consisting of organic material such as cellulose, hemicellulose and lignin as well as inorganic material (Figure 3), where the results are shown in the supplementary data Table S1. Based upon the ICP-AES results we attributed the black specks in the micrographs to $\mathrm{SiO}_{2}$ nanoparticles that cannot be dissolved by [Emim][OAc] [25]. Although the dissolution process was followed until the particle became transparent, since the dissolution rate is linear it is believed this method is useful as a screening method for testing dissolution rates of RS particle dissolution at other temperatures. While the particle is dissolving, it should be noted that the light intensity of the [Emim] [OAc] around the particle is becoming darker, which has also been confirmed by UV-VIS spectroscopy measurements (data not shown).

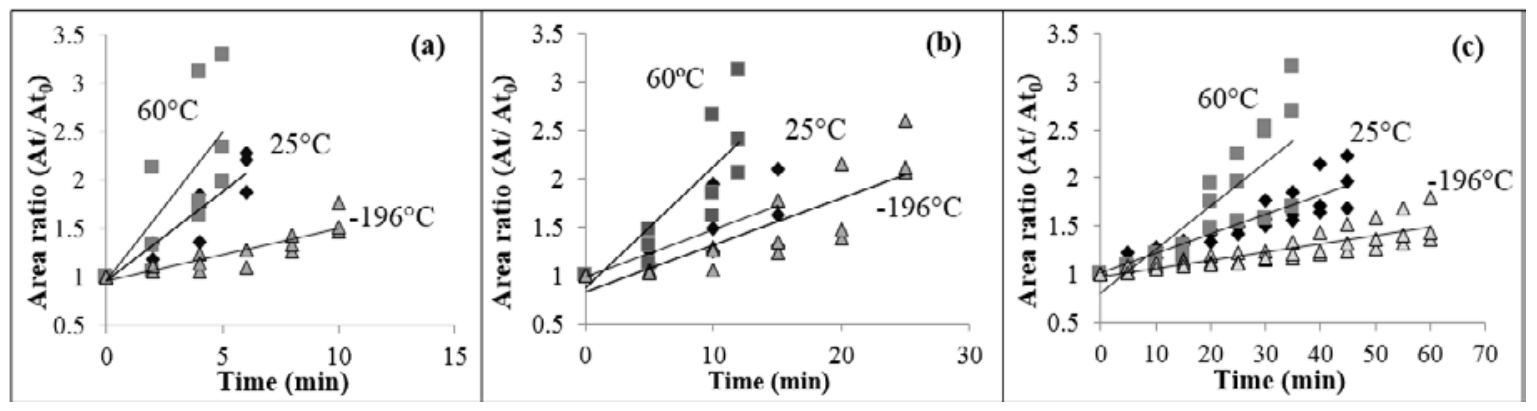

Figure 4: RS particle area ratio heated at (a) $160^{\circ} \mathrm{C}$, (b) $140^{\circ} \mathrm{C}$ and (c) $120^{\circ} \mathrm{C}$ vs. time. 


\section{Effect of milling temperature and hot plate temperature on RS dissolution time}

Both ball milling temperature and [Emim][OAc] temperature significantly impact RS particle dissolution time as shown in Figure 6. For example, the elevated milling temperature at $60^{\circ} \mathrm{C}$ and heating at $160^{\circ} \mathrm{C}$ had the shortest dissolution time of $5 \mathrm{~min}$, whereas dissolving RS particles milled at $-196^{\circ} \mathrm{C}$ when heated at $120^{\circ} \mathrm{C}$ in [Emim] [OAc] led to a prolonged dissolution time of $1 \mathrm{hr}$. The chemistry of the dissolution of biomass in ionic liquids has been reported previously and higher temperatures are more effective in disrupting the hydrogen bonds of the 3D cellulose micro-bundles [26]. We assume the temperatures of the RS powder inside the milling jar, internal milling jar surface, milling jar and milling ball are all the same after heating for two hours in the oven prior to milling. Furthermore, heat generated from the ball kinetic energy resulting from the stainless steel milling ball striking the RS powder is also contributed to greater amorphization of cellulose at elevated temperature and greater surface damage and higher area [5]. As mentioned in the BET analysis section, the $60^{\circ} \mathrm{C}$ milled powder had the highest surface area and dissolved the fastest as a result due to the fractured surface of the milled RS particles. Therefore, the milling temperature significant impacts the particles' micro-crystallinity (chemical bonding) and surface area as reported based upon XRD, BET, and FTIR analysis. These changes are attributed to the disruption of the cellulose structure and cleavage of carbonate and lignin linkages which releases hemicelluloses enhancing the dissolution rate in [Emim] [OAc] [27]. At the highest temperature [Emim][OAc] viscosity is expected to be lower which promotes diffusion of particle chemical species away

(a) Area ratio results

\begin{tabular}{|c|c|c|c|c|c|c|}
\hline Heating Temp. & \multicolumn{2}{|c|}{$1 \mathbf{1 6 0}^{\circ} \mathbf{C}$} & \multicolumn{2}{c|}{$1 \mathbf{1 4 0}^{\circ} \mathbf{C}$} & \multicolumn{2}{c|}{$\mathbf{1 2 0}^{\circ} \mathbf{C}$} \\
\hline Milling Temp. & Equation (y) & $\mathbf{R}^{\mathbf{2}}$ & Equation (y) & $\mathbf{R}^{\mathbf{2}}$ & Equation (y) & $\mathbf{R}^{\mathbf{2}}$ \\
\hline $25^{\circ} \mathrm{C}$ & $0.19 x+0.96$ & 0.9 & $0.05 x+0.97$ & 0.6 & $0.02 x+1.01$ & 0.9 \\
\hline $60^{\circ} \mathrm{C}$ & $0.31 x+0.96$ & 0.6 & $0.13 x+0.87$ & 0.7 & $0.04 x+0.81$ & 0.7 \\
\hline$-196^{\circ} \mathrm{C}$ & $0.05 x+0.95$ & 0.8 & $0.05 x+0.83$ & 0.7 & $0.01 x+0.97$ & 0.7 \\
\hline
\end{tabular}

(b) Light intensity ratio results

\begin{tabular}{|c|c|c|c|c|c|c|}
\hline Heating temp. & \multicolumn{2}{|c|}{$160^{\circ} \mathrm{C}$} & \multicolumn{2}{c|}{$140^{\circ} \mathrm{C}$} & \multicolumn{2}{c|}{$120^{\circ} \mathrm{C}$} \\
\hline Milling Temp. & Equation $(y)$ & $R^{2}$ & Equation $(y)$ & $R^{2}$ & Equation $(y)$ & $R^{2}$ \\
\hline $25^{\circ} \mathrm{C}$ & $0.04 x+0.68$ & 0.9 & $0.02 x+0.69$ & 0.9 & $0.004 x+0.69$ & 0.8 \\
\hline $60^{\circ} \mathrm{C}$ & $0.07 x+0.64$ & 0.9 & $0.02 x+0.72$ & 0.9 & $0.01 x+0.66$ & 0.9 \\
\hline$-196^{\circ} \mathrm{C}$ & $0.03 x+0.65$ & 0.8 & $0.01 x+0.65$ & 0.9 & $0.01 x+0.62$ & 0.9 \\
\hline
\end{tabular}

Table 1: (a) Linear regression results of RS particles' area ratios in [Emim][OAc] from Figure 4, (b) RS particles light intensity ratios in [Emim][OAc] from Figure 5 from the solid surface [28] as well as transports unreacted [Emim] [OAc] to surface, which then penetrates into the fractured particle cell wall reacting with the cellular material leading to particle swelling [29]. Hence, both milling temperature and [Emim] [OAc] temperature synergistically impact the RS dissolution rate.

\section{Proposed dissolution process model}

In Figure 7(a) and (b) is an illustration of the overall dissolution process based upon the milling temperatures from the particle point of view consisting of the three sequential steps. The first step is shown in Figure 7(a) illustrates the relationship between the ball milling temperature and rice straw particle morphology changes corresponding to the particles' surface structure and the core-shell phenomenon when milled at temperatures of $60^{\circ} \mathrm{C}, 25^{\circ} \mathrm{C}$, and $-196^{\circ} \mathrm{C}$. Elevated grinding temperature resulted in a cellulose crystallinity index decrease based upon equation 1 . The particle color change is also influenced by the milling temperature and increased roughness of the outer surface shell of the RS powders with higher milling temperature as seen in step 1 based upon FTIR, XRD and BET results. The second step Figure 7(b) describes the overall dissolution process model on the glass slide observed by optical microscopy. Based upon the microphotograph image, step 3 in Figure 7(b) the time-elapsed dissolution showed particle swelling was dependent on the milling temperatures. As the dissolution progressed, the light intensity ratio approached 1.0. As mentioned earlier, ball milling temperature impacts particle amorphization, specific surface area and reduces the degree of polymerization. Therefore, the dissolution model in Figure 7 ties together the rice particle physical changes with the dissolution process overall. It should be noted that particle dissolution is strongly coupled with the swelling rate and milling temperature. In general, biomass particle swelling is often observed when heated in [Emim] [OAc] with swelling proceeding dissolution. The presented results indicate that particle swelling as measured by cross-sectional area ratios shows great variability then light intensity ratios. Hence, light intensity ratios are a better monitor for tracking the dissolution rate since it is linear with heating time allowing predicting the endpoint, which has also been confirmed independently using confocal microscopy.

\section{Conclusion}

The rice straw chemical composition, crystallinity and particle surface area were strongly impacted by the milling temperatures which impacted the dissolution rate in [Emim][OAc]. That is higher grinding temperature reduced the cellulose crystallinity, accelerating RS dissolution rate in $[\mathrm{Emim}][\mathrm{OAc}]$ at higher heating temperatures,

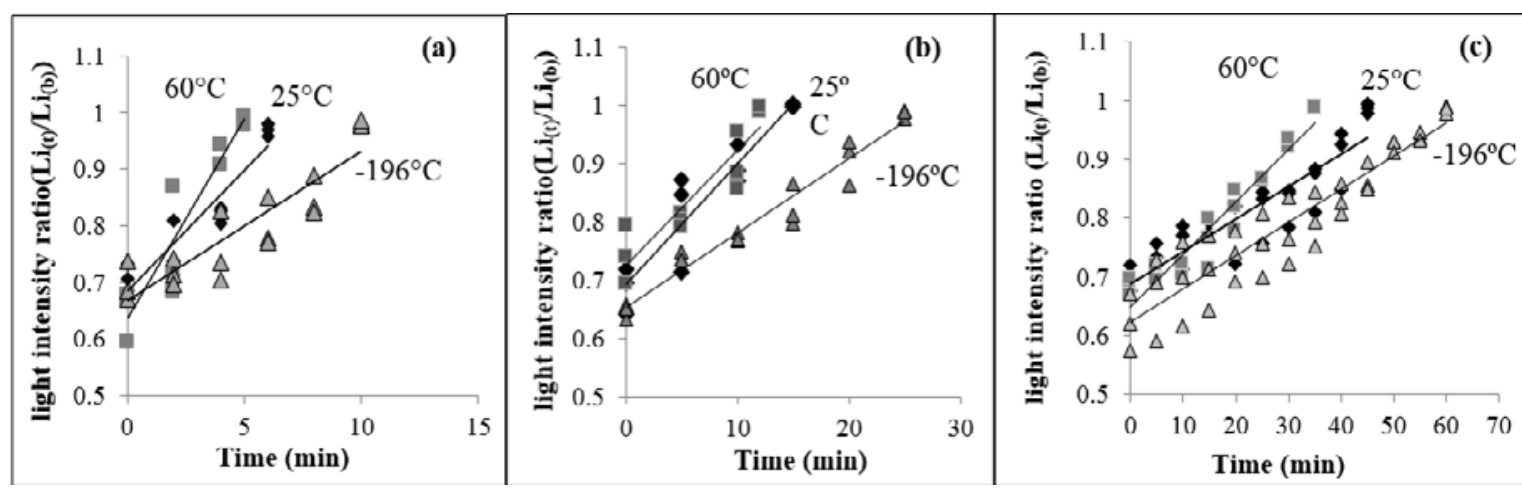

Figure 5: RS Particle Light intensity ratio heated at (a) $160^{\circ} \mathrm{C}$, (b) $140^{\circ} \mathrm{C}$ and (c) $120^{\circ} \mathrm{C}$ vs. time. 
Citation: Myint HH, Kurniawan W, Hinode H, Sein NN, Salim C, et al. (2015) Dissolution Model of Ball Milled Rice Straw Particles in 1-Ethyl-3-Methyl Imidazolium Acetate at Elevated Temperature. J Bioprocess Biotech 5: 260 doi:10.4172/2155-9821.1000260

Page 6 of 7

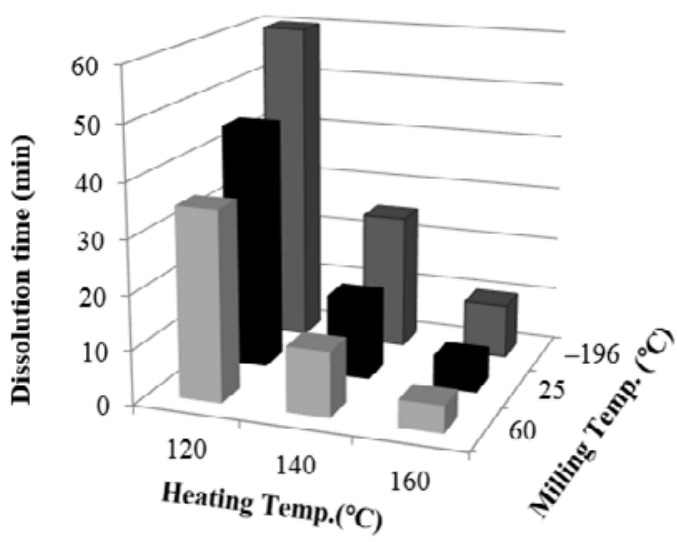

Figure 6: The relationship between ball milling temperature and heating temperature of rice straw particle dissolution in [Emim] $[\mathrm{OAc}]$ as the function times.

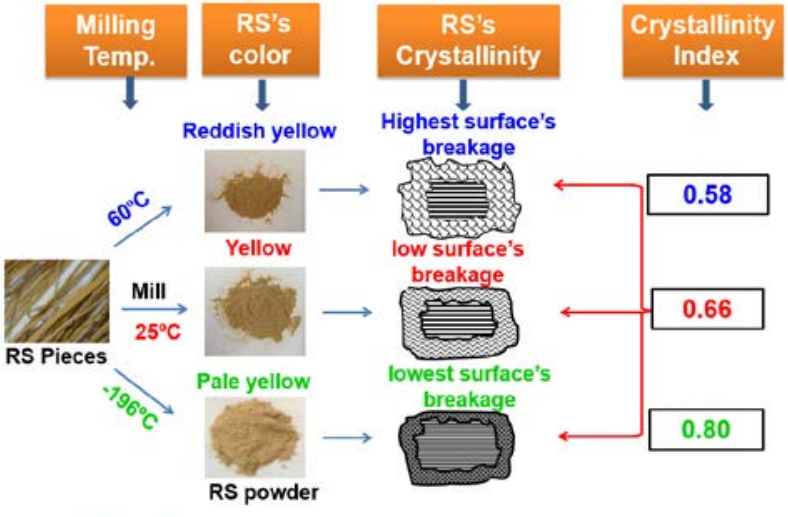

Step 1 Ball milled RS particle's damage

Figure 7a: Step 1: Illustration of ball milling temperature impact on RS powder.

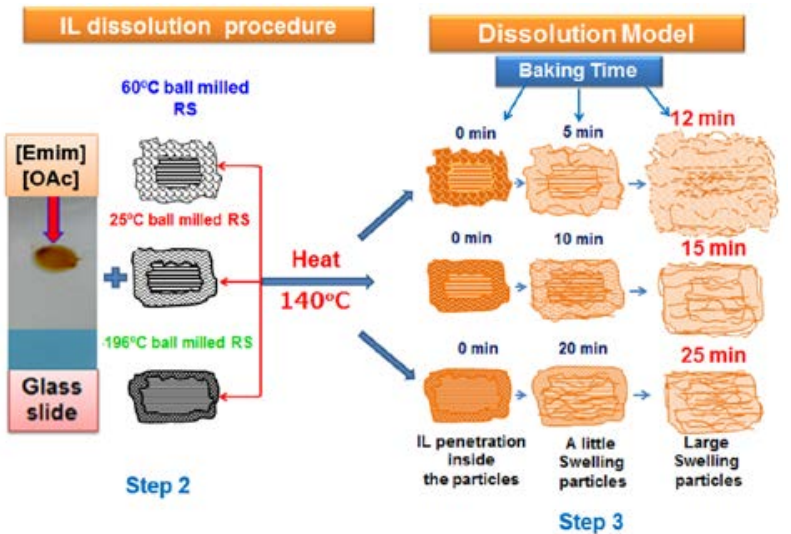

Figure 7b: Step 2: Illustration of RS dissolution process at $140^{\circ} \mathrm{C}$; Dissolution procedure and Step 3: dissolution model as the function of heating times at $140^{\circ} \mathrm{C}$.

which resulted in faster dissolution times. The particle light intensity ratio gradually increased linearly, thinning with heating time as the rectangular particle dissolved. The particle area ratio varied strongly with the milling temperature and fitting the change in the area ratio vs. heating time showed greater variation than the light intensity ratio vs. heating time due inhomogeneity in the particles. From these results, it appears that Japanese rice straw particle dissolution follows a linear relation overall with heating time in [Emim] [OAc]. The results indicate that since the particle dissolves from the surface, making the particles thinner while surface area expands. Given the dissolution follows a linear relation with heating time and increases with temperature, the model put forward also could be used to predict dissolution at intermediate temperature and with other types of biomass.

\section{Author's Contributions}

The first author (HHM) planned the research study, constructed the dissolution model, carried out the experiment and analysis, interpreted the results and wrote the manuscript. J.S. Cross conceptualized and reviewed the manuscript critically.

\section{Acknowledgements}

The first author (HHM) thanks the Japan International Cooperation Agency (JICA) for the scholarship that supported her academic study making this research possible. The authors also greatly acknowledge Tokyo Institute of Technology Analysis Center for their analysis training and use of their analytical equipment. This research was partially supported by the Tokyo Institute of Technology Academy for Co-creative Education of Environment and Energy Science (ACEEES) program.

\section{References}

1. Alvira P, Tomás-Pejó E, Ballesteros M, Negro MJ (2010) Pretreatment technologies for an efficient bioethanol production process based on enzymatic hydrolysis: A review. Bioresour Technol 101: 4851- 4861.

2. Swatloski RP, Spear SK, Holbrey JD, Rogers RD (2002) Dissolution of cellulose [correction of cellose] with ionic liquids. J Am Chem Soc 124: 4974-4975.

3. Ogura T, Date Y, Kikuchi J (2013) Differences in Cellulosic Supramolecula Structure of Compositionally Similar Rice Straw Affect Biomass Metabolism by Paddy Soil Microbiota. PLoS One 8: e66919.

4. Yu Y, Wu H (2010) Effect of ball milling on the hydrolysis of microcrystalline cellulose in hot-compressed water. AIChE Journal 57: 793-800.

5. Suryanarayana C (2001) Mechanical alloying and milling. Prog Mater Sci 46 $1-184$

6. Hsu TC, Guo GL, Chen WH, Hwang WS (2010) Effect of dilute acid pretreatment of rice straw on structural properties and enzymatic hydrolysis. Bioresour Technol 101: 4907-4913.

7. Singh R, Tiwari S, Srivastava M, Shukla A (2014) Microwave assisted alkali pretreatment of rice straw for enhancing enzymatic digestibility. Journal of Energy 2014: 1-7.

8. Kim SB, Lee SJ, Lee JH, Jung YR, Thapa LP, et al. (2013) Pretreatment of rice straw with combined process using dilute sulfuric acid and aqueous ammonia. Biotechnol Biofuels 6: 109.

9. Gírio FM, Fonseca C, Carvalheiro F, Duarte LC, Marques S, et al. (2010) Hemicelluloses for fuel ethanol: A review. Bioresour Technol 101: 4775-4800.

10. Arora R, Manisseri C, Li C, Ong MD, Scheller HV, et al. (2010) Monitoring and analyzing process streams towards understanding ionic liquid pretreatment of switchgrass (Panicum virgatum L.). Bioenerg Res 3: 134-145.

11. Li C, Knierim B, Manisseri C, Arora R, Scheller HV, et al. (2010) Comparison of dilute acid and ionic liquid pretreatment of switchgrass: Biomass recalcitrance, delignification and enzymatic saccharification. Bioresour Technol 101: 4900-4906.

12. Nguyen TA, Kim KR, Han SJ, Cho HY, Kim JW, et al. (2010) Pretreatment of rice straw with ammonia and ionic liquid for lignocellulose conversion to fermentable sugars. Bioresour Technol 101: 7432-7438.

13. Zavrel M, Bross D, Funke M, Büchs J, Spiess AC (2009) High-throughput screening for ionic liquids dissolving (ligno-)cellulose. Bioresour Technol 100: 2580-2587.

14. Deguchi S, Tsujii K, Horikoshi K (2008) Crystalline-to-amorphous transformation of cellulose in hot and compressed water and its implications for hydrothermal conversion. Green Chem 10: 191-196. 
Citation: Myint HH, Kurniawan W, Hinode H, Sein NN, Salim C, et al. (2015) Dissolution Model of Ball Milled Rice Straw Particles in 1-Ethyl-3-Methyl Imidazolium Acetate at Elevated Temperature. J Bioprocess Biotech 5: 260 doi:10.4172/2155-9821.1000260

15. Olsson C Idström A, Nordstierna L, Westman G (2014) Influence of water on swelling and dissolution of cellulose in 1-ethyl-3-methylimidazolium acetate. Carbohydr Polym 99: 438-446.

16. Ang TN, Ngoh GC, Chua AS, Lee MG (2012) Elucidation of the effect of ionic liquid pretreatment on rice husk via structural analyses. Biotechnol Biofuels 5: 67.

17. Tarley CR, Arruda MA (2004) Biosorption of heavy metals using rice milling byproducts. Characterisation and application for removal of metals from aqueous effluents. Chemosphere 54: 987-995.

18. Chen JJ, Lii CY, Lu AS (2003) Physicochemical and morphological analyses on damaged rice starches. J Food Drug Anal 11: 283-289.

19. Hu S, Hsieh YL (2014) Preparation of activated carbon and silica particles from rice straw. ACS Sustainable Chem Eng 2: 726-734

20. Segal L, Creely JJ, Martin Jr AE, Conrad CM (1959) An empirical method for estimating the degree of crystallinity of native cellulose using the X-ray diffractometer. Text Res J 29: 786-794.

21. Wi SG, Choi IS, Kim KH, Kim HM, Bae HJ (2013) Bioethanol production from rice straw by popping pretreatment. Biotechnol Biofuels 6: 166 .

22. Singh S, Cheng G, Sathitsuksanoh N, Wu D, Varanasi P, et al. ( 2015) Comparison of different biomass pretreatment techniques and their impact on chemistry and structure. Front Energy Res 2: 1-12.
23. Thy P, Jenkins BM, Grundvig S, Shiraki R, Lesher CE (2006) High temperature elemental losses and mineralogical changes in common biomass ashes. Fue 85: 783-795.

24. Cheng G, Varanasi $P$, Arora R, Stavila V, Simmons BA, et al. (2012) Impact of ionic liquid pretreatment conditions on cellulose crystalline structure using 1-ethyl-3-methylimidazolium acetate. J Phys Chem B 116: 10049-10054.

25. Van Soest PJ (2006) Rice straw, the role of silica and treatments to improve quality. Anim Feed Sci Technol 130: 137-171.

26. da Costa Lopes AM, João KG, Morais ARC, Bogel-Lukasik E, Bogel-Lukasik R (2013) lonic liquids as a tool for lignocellulosic biomass fractionation. Sustain Chem Process 1: 1-31.

27. Casas A, Palomar J, Alonso MV, Olieta M, Omarb S, et al. (2012) Comparison of ignin and cellulose solubilities in ionic liquids by COSMO-RS analysis and experimental validation. Ind Crops Prod 37: 155-163

28. Pinkert A, Ang KL, Marsh KN, Pang S (2011) Density, viscosity and electrical conductivity of protic alkanolammonium ionic liquids. Phys Chem Chem Phys 13: $5136-5143$

29. Duan X, Xu J, He B, Li J, Sun Y (2011) Preparation and rheological properties of cellulose/chitosan homogeneous solution in ionic liquid. BioResources 6 : 4640-4651. 